\title{
Vertical Raindrop Size Distribution in Central Spain: A Case Study
}

\author{
Roberto Fraile, ${ }^{1}$ Amaya Castro, ${ }^{1}$ Miguel González-Colino, ${ }^{1}$ Elisabeth Alonso-Blanco, ${ }^{2}$ \\ María Fernández-Raga, ${ }^{1}$ Covadonga Palencia, ${ }^{1}$ and Ana I. Calvo ${ }^{1}$ \\ ${ }^{1}$ Department of Physics, IMARENAB, University of León, 24071 León, Spain \\ ${ }^{2}$ Research Centre for Energy, Technology and Environment (CIEMAT), 28040 Madrid, Spain
}

Correspondence should be addressed to Roberto Fraile; roberto.fraile@unileon.es

Received 12 March 2015; Accepted 26 July 2015

Academic Editor: Klaus Dethloff

Copyright (C) 2015 Roberto Fraile et al. This is an open access article distributed under the Creative Commons Attribution License, which permits unrestricted use, distribution, and reproduction in any medium, provided the original work is properly cited.

A precipitation event that took place on 12 October 2008 in Madrid, Spain, is analyzed in detail. Three different devices were used to characterize the precipitation: a disdrometer, a rain gauge, and a Micro Rain Radar (MRR). These instruments determine precipitation intensity indirectly, based on measuring different parameters in different sampling points in the atmosphere. A comparative study was carried out based on the data provided by each of these devices, revealing that the disdrometer and the rain gauge measure similar precipitation intensity values, whereas the MRR measures different rain fall volumes. The distributions of drop sizes show that the mean diameter of the particles varied considerably depending on the altitude considered. The level at which saturation occurs in the atmosphere is decisive in the distribution of drop sizes between 2,700 m and 3,000 m. As time passes, the maximum precipitation intensities are registered at a lower height and are less intense. The maximum precipitation intensities occurred at altitudes above $1,000 \mathrm{~m}$, while the maximum fall speeds are typically found at altitudes below $700 \mathrm{~m}$.

\section{Introduction}

Precipitation is a poorly quantified aspect within the hydrological cycle [1]. When studying precipitation events, they can be approached from different perspectives and with different types of instrumentation. A rain gauge is the simplest and least costly instrument for determining the amount of precipitation that has fallen at surface level in a specific site and in a specific time interval. However, many types of scientific research connected with rainfall require knowledge on the raindrop size distribution. This entails the use of more sophisticated instrumentation, such as a disdrometer, which will provide the drop size spectrum in a specific location and at a constant altitude while the measurements are taken. Disdrometers make use of mechanical, microwaves, or optical techniques to measure drop sizes [2-4] and although not error-free $[5,6]$, they are becoming increasingly important for the scientific community [7-9].

An important characteristic of clouds and precipitation is the raindrop size spectrum. The nature of clouds means it is necessary to use techniques such as remote sensing. One instrument which uses remote sensing, more precisely electromagnetic waves in order to study precipitation, is Micro Rain Radar (MRR). This is a very useful device, capable of analyzing the distribution of raindrop sizes in a vertical column with an acceptable temporal and spatial resolution. The remote detection of rainfall using radar is parameterized through the reflectivity factor, which depends on the number of drops and the distribution of sizes. The technical details and limitations of MRR technology have been described in previous studies, along with some applications [10-15].

In order to discover the microphysical mechanisms behind the formation of precipitation, these distributions of drop sizes must be analyzed [16, 17], as the characteristics of the drop size distributions depend on the type of clouds (convective or stratiform) that generate them and their stage of development [18-20].

Another aspect to be taken into account when studying raindrops is their spatial-temporal evolution during the precipitation event. In order to analyze drop size distributions, 
Marshall and Palmer early proposed an exponential distribution [21], which was subsequently generalized by Sekhon and Srivastava [22] and Waldvogel [16]. After several observations demonstrated that an exponential distribution overestimated the number of small drops recorded [23, 24], Ulbrich [25] and Willis [26] introduced the gamma distribution. Other mathematical functions have been proposed to represent drop size distributions [27, 28], but the most widely used ones are the exponential and the gamma distributions, still in use today [29-33].

The two main objectives of this study are the following: on the one hand, to study in detail the precipitation and its development in a vertical profile during a rain event, by means of a MRR, and, on the other hand, to compare the measurements taken using the three different precipitation measurement devices: the rain gauge, the optical disdrometer, and the MRR.

\section{Study Zone}

The study was carried out at the Universidad Politécnica de Madrid, Spain, not far from the urban center. Madrid lies in the center of Spain (at $655 \mathrm{~m}$ asl) and has the typical characteristics of the Mediterranean climate, namely, a highly irregular climate with isolated but high-intensity precipitation events.

The dominant climate in Madrid, conditioned by the topography, is of the Continental Mediterranean type, due to the altitude and the mountains that prevent masses of humid sea air from reaching the zone. As a result, the mountains have colder climatic means, with a notable thermal and pluviometric gradient from the Tajo Valley to the mountains. The main centers of action are the polar front, which discharges masses of moist air, and the Azores high-pressure system. The region is also affected by the urban environment.

The masses of moist air from the Atlantic have great difficulty in reaching the region. This is due to a large extent to the barrier effect of the Central Mountain System, which prevents the passage of masses of moist air. Most of the region receives less than $700 \mathrm{~mm}$ of rain per year. The urban environment of Madrid causes noticeable disruptions to the regional climate; in general, the temperature in the city is higher than in the outskirts. This difference increases in situations of stability due to the action of a thermal highpressure system, and this is when the heat island appears, causing local winds from outside the city towards the inner city. Also, the urban atmosphere is slightly more humid, and precipitation is the same as in the rest of the area.

\section{Materials and Methods}

Three different devices (Figure 1) have been used in this study to measure precipitation intensity in different ways: an optical disdrometer, as described by Fernández-Raga et al. [34], a rainfall gauge, and a Micro Rain Radar (MRR).

The Micro Rain Radar is a Doppler-type meteorological radar pointing upwards and measuring backscattered energy as a function of Doppler frequency shift. The energy received

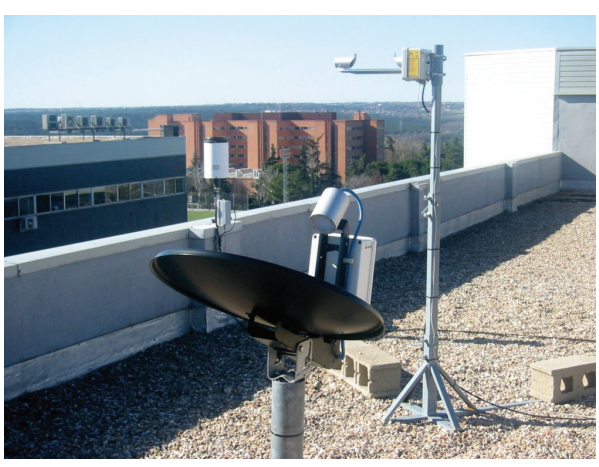

FIGURE 1: Instrumentation used: in the foreground, the Micro Rain Radar (MRR); in the background to the left, a rainfall gauge; and to the right, an optical disdrometer.

within a certain frequency window is assigned to drops in the corresponding velocity window. The drop size is calculated from the drop velocity following Atlas et al. [35]: $v(D)=$ 9.65-10.3 $\exp (-0.6 D)$, where $D$ is in $\mathrm{mm}$ and the velocity in $\mathrm{m} / \mathrm{s}$. This relation is corrected with respect to air density $\rho$ according to [36] as follows: $v(\rho, D)=v\left(\rho_{0}, D\right)\left(\rho_{0} / \rho\right)^{0.4}$.

For the derivation of drop size distributions, the relation between terminal fall velocity $v$ and drop diameter $D$ is used. This relation has been described empirically by Gunn and Kinzer [37] and was later set in analytical form by Atlas et al. [35] (see Figure 5). We have used a generalized form in which a height $h$ (in meters) dependent density correction for the fall velocity $\delta v(h)$ is included:

$$
\begin{aligned}
& v(D)[\mathrm{m} / \mathrm{s}] \\
& =(9.65-10.3 \times \exp (-0.6 \times D[\mathrm{~mm}])) \delta v(h) \\
& \text { for } 0.109 \leq D \leq 6 \mathrm{~mm} .
\end{aligned}
$$

We assume US Standard Atmosphere conditions for the height dependence of air density, and we make use of the relation of Foote and du Toit [36], who found $v \propto$ $\rho^{0.4}$. A second-order approximation for $\delta v(h)$ under these assumptions is

$$
\delta v(h)=\left[1+3.68 \times 10^{-5} h+1.71 \times 10^{-9} h^{2}\right] .
$$

The spatial resolution of the device varies from $35 \mathrm{~m}$ to $200 \mathrm{~m}$ per range class, measuring 29 height levels, each of which is between 35 and 200 meters high. As a result, to all practical effects, the MRR measures columns with an upper height limit that varies from 1,015 meters to 5,800 meters. In fact, the MRR has a height range of 30 levels, although the manufacturer recommends discarding the data from the first of these levels due to the calculation method of Metek [38]. It has a transmission frequency of $24.1 \mathrm{GHz}$, a transmission power of $50 \mathrm{~mW}$, and a sampling time of 10-3600 s.

The data provided each minute by the MRR are the averaged drop spectrum, the rain rate or intensity, the fall velocity, and the radar reflectivity.

The disdrometer used for this study is the Thies Laser Disdrometer, which fully characterizes surface precipitation. 
The device uses laser measurement techniques to include all types of precipitation. It measures the quantity, intensity, particle size, and fall speed. The system calculates the intensity, liquid water content, precipitation range (the diameter and speed of the drops), the meteorological visibility in the rain, and the radar reflectivity. A heating system with controlled temperature makes it possible to take reliable measurements throughout the whole year, and the technology also takes into account the influence of external sources of light. Fluctuations in temperature and contamination of the optics are compensated automatically.

The main features of the disdrometer are the following: a sampling area of $46 \mathrm{~cm}^{2}(23 \mathrm{~cm} \times 2 \mathrm{~cm}), 440$ precipitation classes (22 diameters and 20 speeds), the drop size range that varies from $0.16 \mathrm{~mm}$ to $8 \mathrm{~mm}$, the speed range that varies from $0.2 \mathrm{~m} / \mathrm{s}$ to $20 \mathrm{~m} / \mathrm{s}$, and the minimum intensity that is $0.005 \mathrm{~mm} / \mathrm{h}$. The disdrometer measures continuously, taking an integrated measurement every minute.

The weather station has a tipping bucket rain gauge. The volume of precipitation stored in each box before tipping is $0.1 \mathrm{~mm}$. The system records the time when the tipping mechanism is activated. To determine the amount of water precipitated the number of times the bucket dumps is counted. The following criterion was used to identify the precipitation events during 2008: each dump separated by more than 20 minutes from the previous one was considered as a new rainfall event.

These three instruments provide three series of data on precipitation. Although they all reflect similar rainfall characteristics, they do so on the basis of different parameters, so the data may differ. These differences are referred to in Section 4.5, where the three instruments are compared.

Precipitation events from 2008 were used as the database for this study. The first step was to identify the events with the data from the rainfall gauge, using the criterion that all of the dumps that were less than 20 minutes apart were considered as forming part of the same event. The events were then tabulated and, after applying basic statistical tests, were summarized in a graph that shows the amount of rainfall recorded on a monthly basis throughout the whole year (Figure 2). Subsequently, certain events in the months with the highest precipitation rates were examined in closer detail. This study focuses on the event that occurred on 12 October 2008.

\section{Results and Discussion}

4.1. Pluviometric Study. The data provided by the rain gauge show that 2008 was a slightly irregular year (Figure 2), although this is typical of Madrid's Mediterranean climate. Two periods with high rainfall can be seen, in Spring (April and May) and October. October was the month in 2008 with the maximum amount of rainfall, while July and August were the months with the lowest rate. After making the pluviometric summary for 2008, October was chosen to be studied in greater detail because of the large amount of precipitation recorded: more than $100 \mathrm{~mm}$. The study event occurred in Madrid on 12 October 2008, between 0000 UTC

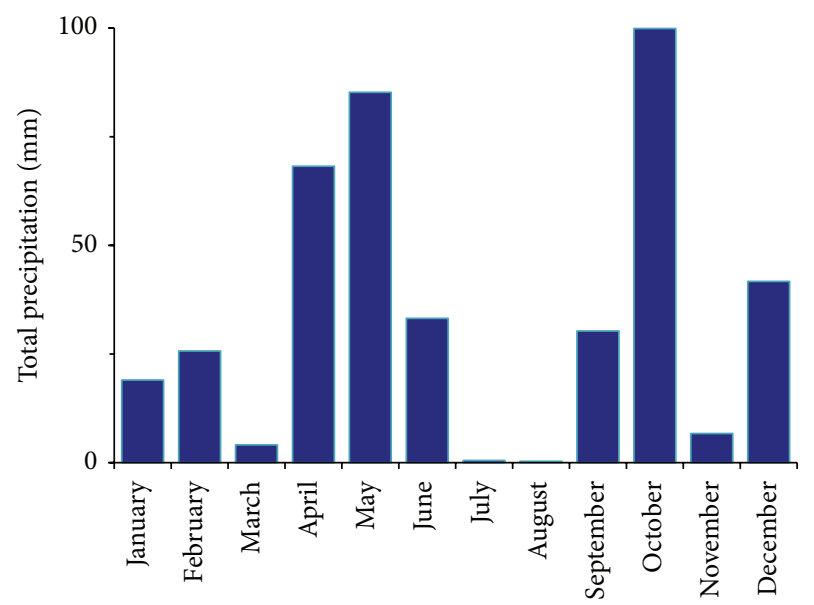

FIGURE 2: Summary of precipitation recorded in 2008 by the weather station in Madrid.

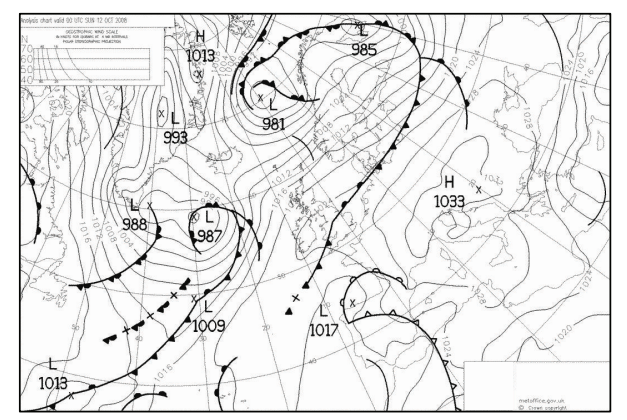

FIgURE 3: Synoptic map for 12 October 2008.

and 0220 UTC, with a total duration of 140 minutes. A total amount of $25.9 \mathrm{~mm}$ of precipitation was recorded, an average precipitation intensity of $11.1 \mathrm{~mm} / \mathrm{h}$ was registered, and a maximum precipitation intensity of $120 \mathrm{~mm} / \mathrm{h}$ was measured.

4.2. Study of the Meteorological Situation. On the study day, the synoptic situation (Figure 3 ) for the study zone reflected major instability in terms of both height and surface, with a cold front entering the study zone from the southwest and a pocket of cold air at higher levels. The Iberian Peninsula was affected in the west and in the Canary Islands by a low, while the eastern zone was under the influence of a high-pressure system with its centre over the Adriatic Sea, introducing a mass of cold air from Central Europe. The study zone (Madrid) is in the center of the peninsula, in a convergence zone of the high-pressure system. At the $500 \mathrm{hPa}$ level, the Iberian Peninsula was under the influence of a low with its centre to the southwest of Cape San Vicente, which reached as far as the Canary Islands. To the west of the peninsula we see the ridge of the high-pressure system with its center in Africa.

Data from the sounding carried out in Madrid $\left(40.50^{\circ} \mathrm{N}\right.$, $3.58^{\circ} \mathrm{W}$, and altitude of $633 \mathrm{~m}$ ) were provided by the University of Wyoming (http:/weather.uwyo.edu/upperair/sounding.html). The vertical profile of the atmosphere for 12 


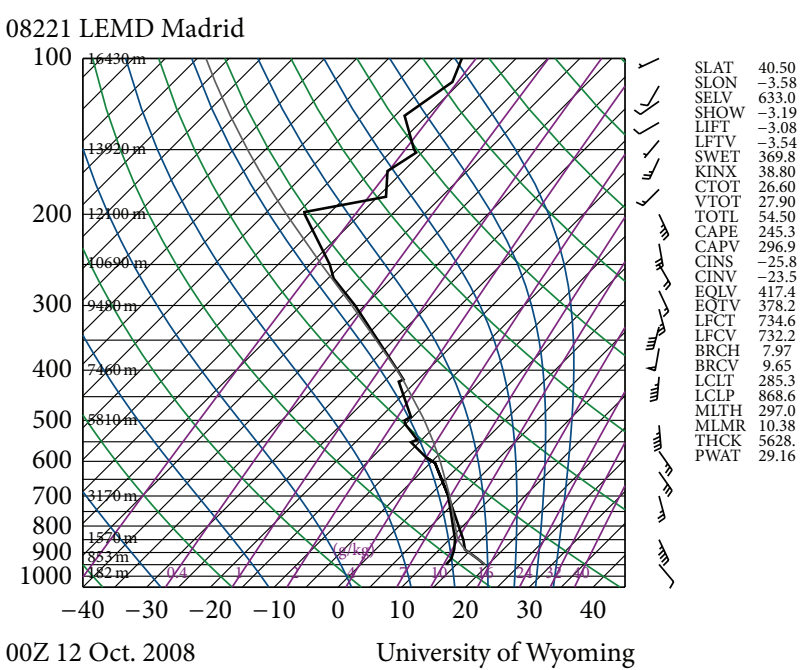

Figure 4: Skew-T diagram of Madrid for 12 October 2008 at 0000 UTC Madrid (http:/weather.uwyo.edu/upperair/sounding .html).

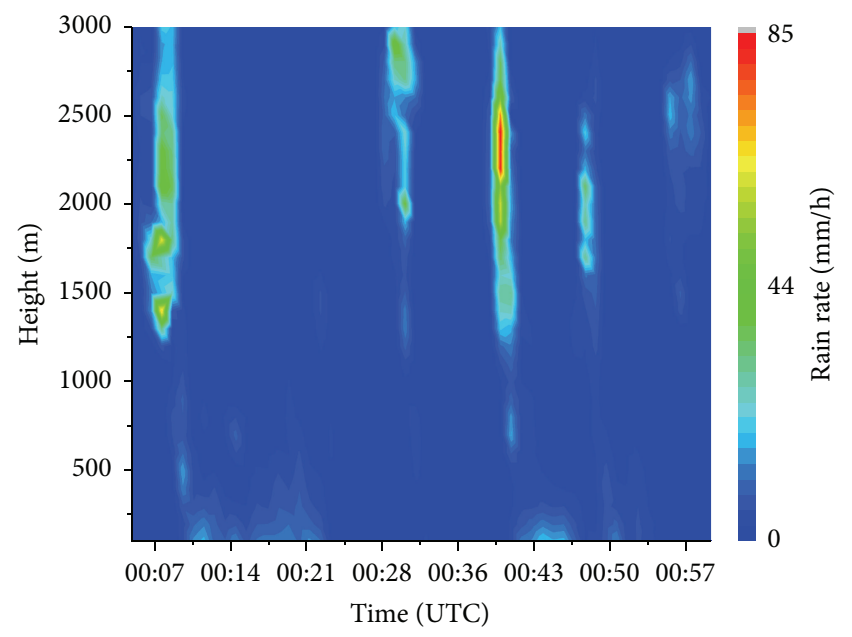

FIGURE 5: Rainfall rate registered by the MRR in the first 60 minutes of rain according to height.

October at 00 UTC indicated high levels of moisture in the atmosphere, together with certain instability. At the beginning of the rain event, the following stability indices confirm the special atmospheric situation on this day: the Showalter index was -3.19 , the CAPE index at $245.3 \mathrm{~J} / \mathrm{kg}$ is relatively high, the LIFT index was -3.08 , the $K$ index was 38.8 , and the TT was 54.5. The Convective Condensation Level (CCL) was at $1099 \mathrm{~m}$. At noon, 12 hours after, the instability decreased as indicated by the Showalter index $(-0.06)$, the LIFT index $(-0.54)$, the $K$ index (23.9), and the TT (49.0). Nevertheless, the CAPE index jumped to $401.8 \mathrm{~J} / \mathrm{kg}$.

In Figure 4 the Skew- $T$ for 12 October at 00 UTC is shown. In the figure, isotherms are represented by upward straight lines in blue, isobars are the blue horizontal lines, dry adiabatic curves are green, saturated wet adiabatic curves are represented by blue curves, and mixing ratio lines are upward pink lines. The vertical temperature profile shown in the Skew- $T$ reveals that the temperature curves of the dew point $\left(T_{d}\right)$ and the state curve corresponding to the temperature $(T)$ are very close together, which indicates high levels of moisture in the atmosphere, even reaching saturation at around 3,000 meters. From 4,500 meters there are no dew point temperature data, and it is not possible to know the moisture above this height. Consequently, it is not possible to determine the vertical profile of the atmosphere accurately. However, it is still of some use for this study, as the data provided by the MRR were obtained in the first $3,000 \mathrm{~m}$ of height.

4.3. Study of the Precipitation Event. During the precipitation event on 12 October over the city of Madrid, the MRR measures the differential reflectivity minute by minute in order to obtain the data shown below. Wind blew from the north, so the slice made by the MRR beam was not always taken on the same point of the cloud but instead cut a different section of the cloud in each particular moment, as it was moving. This cloud movement caused a number of discontinuities, as we will see later on in this paper. Within the event of 140 minutes, this paper studies the first hour, between 0000 UTC and 0100 UTC, as it is the time interval with the highest precipitation intensities.

4.3.1. Rain Intensity. Figure 5 shows the rainfall intensity for each one-minute time interval and each height for the 60 minutes studied, thereby representing the development of rainfall intensity, below $3,000 \mathrm{~m}$. The figure shows that the high intensity intervals are not continuous but instead appear suddenly, are relatively brief, and disappear, appearing once again after a moment of weak precipitation intensity. Five precipitation intervals occur and are represented as a "sloped column." The first interval is the longest one and lasts from 0006 UTC until 0024 UTC.

The maximum intensities of the intervals decrease in height and magnitude; that is, as the minutes pass, the maximums for each interval are at a lower height and are less intense. This is shown in the slightly oblique shape of the "columns," because, over time, the highest intensities are recorded at lower altitude levels. A specific study of the most intense precipitation interval (shown in the third column of Figure 5) is developed in a subsequent epigraph 4.5. The fall speed of these maximums can be calculated based on the slope of the columns.

It is also interesting to note that the maximum precipitation intensities, over $80 \mathrm{~mm} / \mathrm{h}$, are always reached at levels higher than 1,000 meters, with values up to $120 \mathrm{~mm} / \mathrm{h}$. In contrast, the precipitation recorded in the lower levels never exceeds $30 \mathrm{~mm} / \mathrm{h}$. This vertical distribution of rain rates is similar in shape to the one recorded by Peters et al. [12] for high intensities around the Baltic Sea.

4.3.2. Drop Size Distribution. Despite many different formulae available for both size distribution and terminal velocity [28], we have studied the vertical profile of sizes, based on the drop size distribution (DSD) suggested by Marshall and 


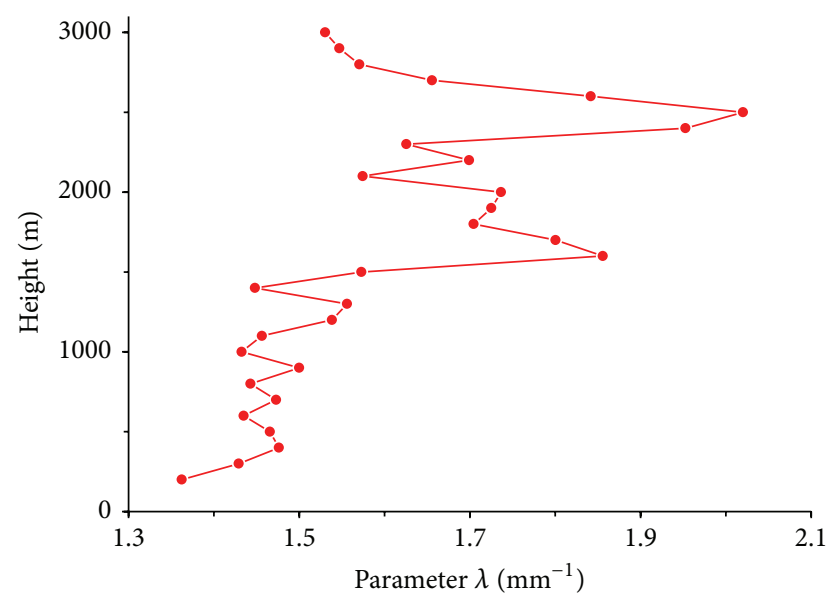

FIGURE 6: Parameter $\lambda$ for the raindrop size spectra at the different heights considered during the hour of precipitation in the 30 height levels studied.

Palmer [21], that is, that raindrop sizes follow an exponential distribution. The exponential probability density function $(\mathrm{PDF})$ is

$$
f(x)=\lambda \exp (-\lambda x) .
$$

The parameter $\lambda$ has three characteristics: it is the only parameter of the PDF, it is easy to calculate, and its significance is easy to interpret. In fact, $1 / \lambda$ represents the mean of the distribution, and its value is commonly used to analyze differences between distributions [39-41]. The method of moments provides a value of $\lambda$ which is the inverse of the mean value $\mu$ of all of the sizes [30]:

$$
\frac{1}{\mu}=\lambda=\frac{\sum_{i=1}^{n} N_{i}}{\sum_{i=1}^{n} d_{i}^{\prime} N_{i}}
$$

where $d_{i}^{\prime}$ is the value taken as being representative of the class $i$ (which ranges from $d_{i}-1$ to $d_{i}$ ) and $N_{i}$ is the number of drops in class $i$.

Figure 6 shows the parameter $\lambda$ during the hour of precipitation in the 30 height levels studied. As we can see in Figure 5, in this time interval the precipitation goes through 5 differentiated stages. The figure thus reflects a global result that partially obscures the processes of the 5 columns of highest precipitation. In general terms, it may be seen that as the height decreases, from the $3,000 \mathrm{~m}$ level to the surface level, the $\lambda$ parameter decreases too (i.e., there is a higher proportion of large drops as we approach the ground). However, if we study this step by step, as the height decreases, we see the following:

(i) Between 3,000 and 2,800 $\mathrm{m}$ condensation processes are probably occurring, and we have distributions with very similar $\lambda$ parameters of slightly more than $1.5 \mathrm{~mm}^{-1}$, with a large number of drops, although these are very small, with a mean size of $0.67 \mathrm{~mm}$.

(ii) In contrast, from $2,800 \mathrm{~m}$ to $2,300 \mathrm{~m}$ the values of the $\lambda$ parameters increase considerably, until reaching a maximum of $2 \mathrm{~mm}^{-1}$ (equivalent to a mean size of $0.5 \mathrm{~mm}$ ), at around $2,500 \mathrm{~m}$, indicating that here there is a smaller size than in the upper region, where the drops become visibly more numerous than in the immediately inferior levels.

(iii) At $2,300 \mathrm{~m}$ a sudden decrease in the $\lambda$ parameter is seen (of $1.62 \mathrm{~mm}^{-1}$ ), indicating that drops with larger sizes appear at this level, which have grown considerably, possibly as a result of coalescence and condensation processes.

(iv) From 2,300 $\mathrm{m}$ to $1,500 \mathrm{~m}$ the $\lambda$ parameter once again increases progressively as we descend in height (i.e., the drops are not so large and the coalescence processes are less intense).

(v) But from 1,500 $\mathrm{m}$ to the ground, the distributions have increasingly lower parameters, of between 1.35 and $1.5 \mathrm{~mm}^{-1}$, indicating that the drops are increasingly and proportionally larger again (between 0.67 and $0.74 \mathrm{~mm}$ ) as a result of having grown by coalescence during their descent within the cloud.

From Skew- $T$ data, we have estimated that the cloud top is at a height of about $4500 \mathrm{~m}$, with a temperature of $-6.5^{\circ} \mathrm{C}$ and a mixing ratio of $4.01 \mathrm{~g} / \mathrm{kg}$. That height is clearly above the MRR sampling volume. It would therefore seem that there is a significant trend for large drops to be frequent at low levels, while small drops are more abundant at higher levels, with three important growth zones: one between 3,000 and $2,800 \mathrm{~m}$, another between 2,500 and 2,300 $\mathrm{m}$ (both above the CCL, which is at 1,099 $\mathrm{m} \mathrm{AGL),} \mathrm{and} \mathrm{another} \mathrm{below} 1,500 \mathrm{~m}$ in its free fall towards the surface level. In these intervals, the rain rates are very different and this has a strong dependence of the shape of the drop size distribution (DSD) on the rain intensity that has also been evidenced by Peters et al. [12]

4.3.3. Fall Speeds. In this section we analyze the fall speed of raindrops using the Micro Rain Radar for the different heights and their temporal evolution. It is necessary to carry out this measure because not all the raindrops fall down always with the same terminal speed [42]. As in the previous cases, the MRR averages the fall speeds of the drops, as shown in Figure 7. One of the differences with Figure 5 is the following: while in Figure 5 the maximum precipitation intensities are reached in high levels, the maximum speeds are generally reached below $700 \mathrm{~m}$, with values that oscillate between 7 and $9 \mathrm{~m} / \mathrm{s}$, with maximums at surface level.

From 0054 UTC onwards (the time period corresponding to the last "column"), the fall speeds are very low, and, in Figure 5, we see that in this time period there is an interval with very low precipitation intensity at high levels.

4.4. Study of the Interval of the Highest Precipitation Intensity. We will now analyze in detail the behavior of raindrops during a short time interval of 8 minutes within the 60 minutes of the event. We have chosen the interval that contains the maximum precipitation intensity, and therefore the results obtained are not masked by the average of the successive intervals of higher and lower precipitation intensities. 


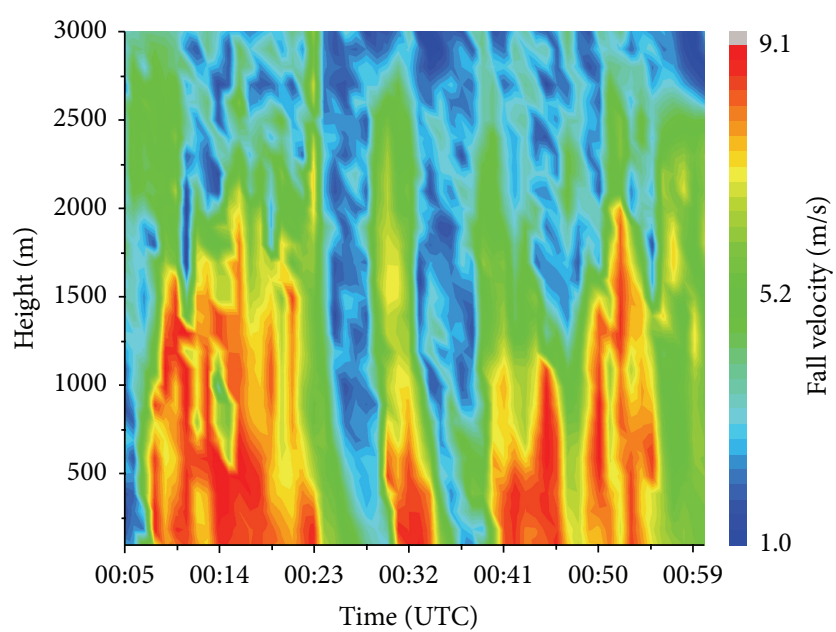

FIGURE 7: Fall speeds for raindrops at different heights during the first hour of the event.

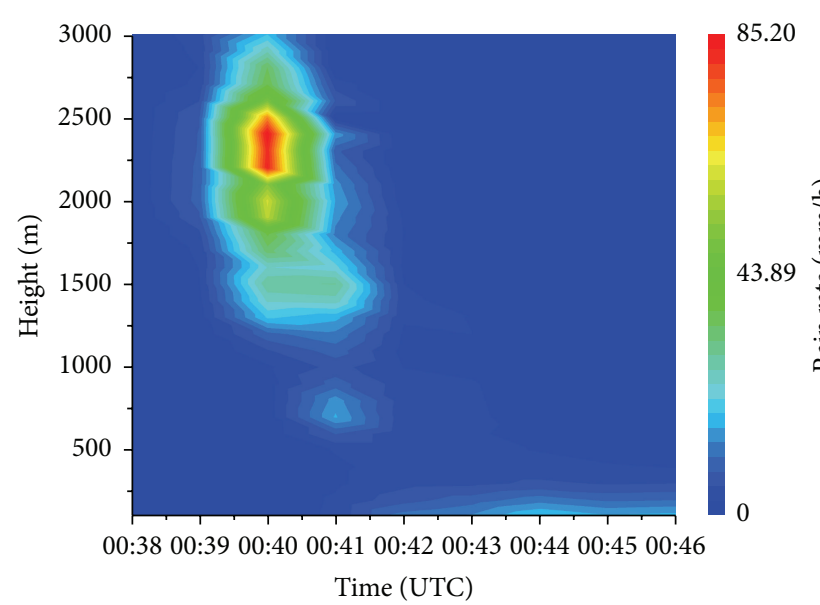

FIGURE 8: Time-height cross section of rain rates recorded by the MRR in 8 minutes of precipitation.

The maximum precipitation intensity in the event was recorded between 0038 and 0046 UTC, with more than $85 \mathrm{~mm} / \mathrm{h}$. Figure 8 shows the oblique shape of the "column," due to the fact that the zones of maximum intensity decrease in height and magnitude as time progresses, until being very weak at levels close to the surface. The fall velocity in the zone of maximum rain rate over the sampling point of the MRR has been estimated at $23 \mathrm{~m} / \mathrm{s}$, perhaps due to the downdraft. Curiously enough, this fall velocity can be more than twice the maximum measured raindrop fall velocity from Figure 7 $(9.1 \mathrm{~m} / \mathrm{s})$.

Another remarkable singularity is the symmetry shown by the precipitation intensities in an interval of around two minutes, between 1,800 and $2,700 \mathrm{~m}$. A transverse slice has been taken at the height of 2,200 meters and is shown in Figure 9, revealing symmetry in time on both sides of the peak of intensity. First, the intensity increases with time (at a rate of $5.4 \mathrm{~mm} \mathrm{~h}^{-1} \mathrm{~min}^{-1}$ ) until reaching a maximum, and then it decreases at a similar rate $\left(4.9 \mathrm{~mm} \mathrm{~h}^{-1} \mathrm{~min}^{-1}\right)$, until

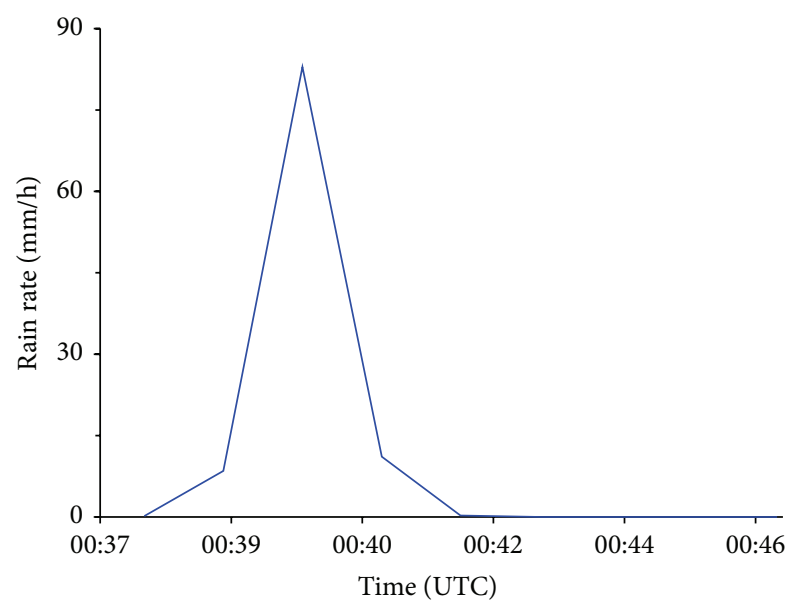

FIGURE 9: Evolution of the rain rate in a transverse slice at a height of $2,200 \mathrm{~m}$.

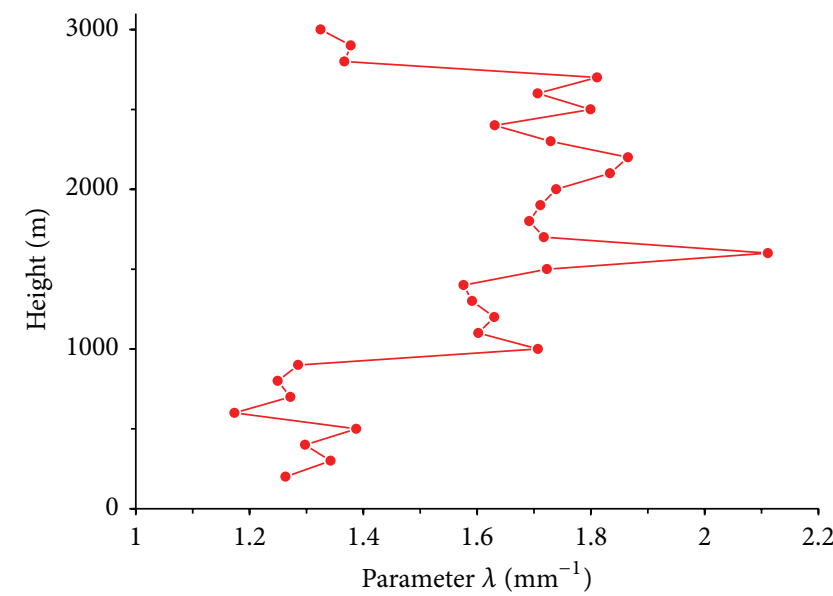

FIGURE 10: Parameter $\lambda$ of the drop size distribution at the different heights considered.

reaching the initial values, subsequently maintaining them constant over time.

If we assume that the drop size spectrum fits a Marshall and Palmer distribution, the characteristic $\lambda$ parameter of the exponential distribution may be calculated (Figure 10). Below $2,800 \mathrm{~m}$, a linear dependence has been observed between the variables represented (height and $\lambda$ parameter). This linear relation was found to be significant for 24 degrees of freedom, with a significance level of $5 \%$, meaning that the $\lambda$ parameter increases linearly with height.

In contrast, between $2,800 \mathrm{~m}$ and $3,000 \mathrm{~m}$, the $\lambda$ parameters have values that remain constant between 1.32 and $1.38 \mathrm{~mm}^{-1}$, with a high proportion of large drops (between 0.72 and $0.76 \mathrm{~mm}$ ). At $2,800 \mathrm{~m}$ the value of $\lambda$ suddenly increases to $1.8 \mathrm{~mm}^{-1}$ indicating that a large number of drops of smaller sizes are found at this level (with mean values of around $0.56 \mathrm{~mm}$ ). From $2,800 \mathrm{~m}$ to $1,000 \mathrm{~m}$, the parameter progressively decreases as we descend in height (i.e., there are increasingly fewer drops, but they are larger), with $\lambda$ values that decrease from $1.87 \mathrm{~mm}^{-1}$ to $1.57 \mathrm{~mm}^{-1}$ (the average 


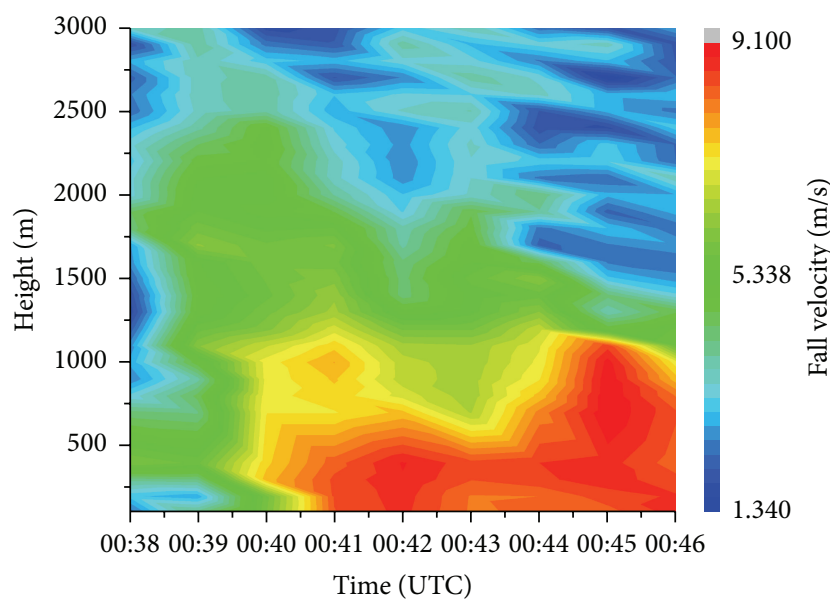

FIGURE 11: Drop fall velocity at different heights during the 8 minutes studied.

diameters of the drops increase from $0.53 \mathrm{~mm}$ to $0.64 \mathrm{~mm}$ ). Precisely in the CCL, the value of the parameter abruptly decreases (with mean diameters of $0.78 \mathrm{~mm}$ ). Finally, from the CCL to the ground level the low $\lambda$ values indicate the presence of increasingly larger drops.

Figure 11 shows how the speeds increase with time and are greater at heights of less than $500 \mathrm{~m}$. The maximum speeds are reached at low levels. Close to the surface the drops were larger, and as a result their terminal velocity will be greater than that of the small drops which are predominant at the highest levels. These high speeds may partly explain the increase in size of the drops at the lowest levels. Due to the fact that the growth of the drops occurs as a result of coalescence and the likelihood of this increases with speed, an increase in the speed will lead to an increase in the size of the drops in a feedback process.

4.5. Comparative Study of the Rain Measurements. This section compares the data provided by the three different instruments used in the study for collecting rain samples. As mentioned above, each instrument uses a different method and thus measures rain on different sampling volumes (the rain gauge and the disdrometer measure at ground level, and the MRR measures in a column of 3,000 $\mathrm{m}$ at 30 height levels). However, the differences should be explicable from this perspective, as they all measure precipitation intensities.

Figure 12 shows the precipitation intensities registered by each of the three devices: the rain gauge and the disdrometer at surface level and the MRR, where an average has been used of the precipitation intensities at the levels of 200 and $300 \mathrm{~m}$ above surface level. Here we may see the following:

(i) There are important similarities between the intensity measurements obtained with the disdrometer and the rain gauge, as described previously in García-Vila et al. [43].

(ii) The rain gauge records slightly higher intensities than the disdrometer, and these differences are more noticeable in the intensity peaks.

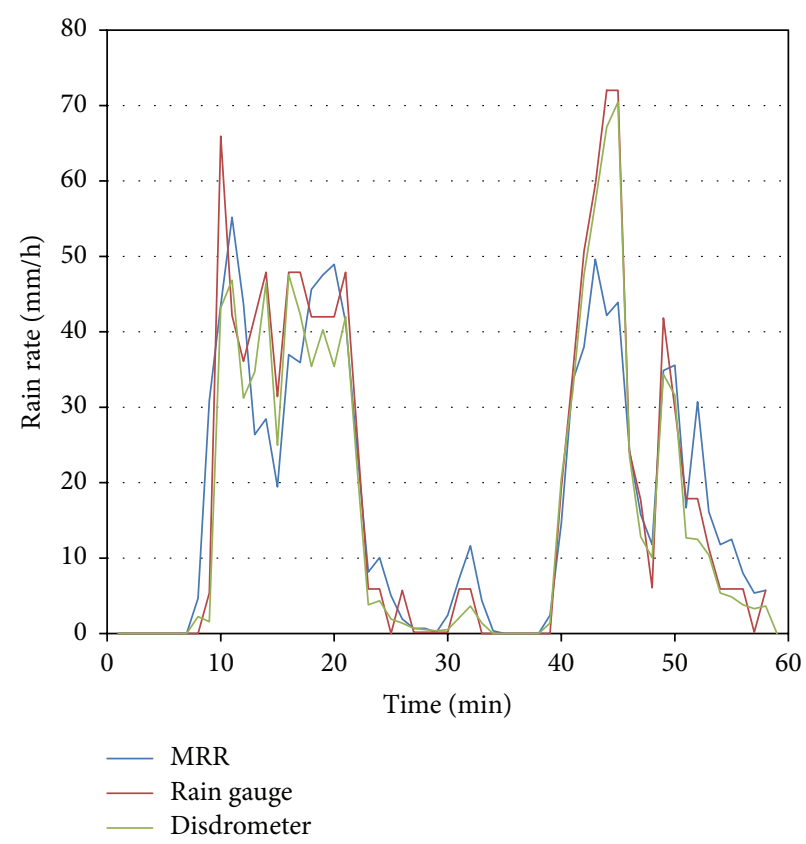

FIGURE 12: Comparison of the different precipitation intensities measured with the three instruments.

(iii) In the low intensity values, the rain gauge does not correspond with the disdrometer, as the former measures the intensity using dumps, that is, discretely, so in the minutes when a dump has not been completed, these are shown with an intensity of 0 . In contrast, the disdrometer is capable of determining even very small precipitation intensities.

(iv) The moments of change in the precipitation intensity are detected almost simultaneously or, at least, within the same minute in all three instruments.

(v) The maximum precipitation intensities recorded by the MRR at 200 and $300 \mathrm{~m}$ are lower than those recorded at surface level by the rain gauge and the disdrometer. In contrast, when the rain gauge and the disdrometer register intensities below $20 \mathrm{~mm} / \mathrm{h}$, the MRR normally overestimates the rain rate.

(vi) Consequently, the MRR presents similar results to the ones obtained using the rain gauge and the disdrometer whenever the intensities measured are not extreme intensities, since the standard deviation of the rain rate in the MRR is $17.5 \mathrm{~mm} / \mathrm{h}$, but 22.1 and $20.3 \mathrm{~mm} / \mathrm{h}$ in the rain gauge and the disdrometer, respectively.

(vii) As the precipitation intensity is not measured the same way or using exactly the same sampling volume, the intensities are slightly different in the case of the disdrometer and the rain gauge and more different between these two and the MRR. These differences have also been observed by other authors [10,44].

To sum up, the comparison between these three instruments offers promising results, especially in the case of the 
rain gauge and the disdrometer, with the exception of the errors that are inherent to each device. On the other hand, the Micro Rain Radar reveals certain proportionality with respect to the other two instruments in spite of the fact that the measurements do not coincide exactly. Nevertheless, the objective of the MRR is to take measurements at different heights and compare precipitation behavior between various levels within the cloud.

\section{Conclusions}

On 12 October 2008 intense precipitation was recorded in an atmosphere characterized by high relative moisture, major instability, and a cold front that affected the study area.

On fitting the drop size distribution to a Marshall and Palmer distribution using the method of moments, it was found that the $\lambda$ parameter of this distribution is linearly dependent on the height until $2,700 \mathrm{~m}$. As a result, the mean diameter of the particles decreases with height and varies between $0.75 \mathrm{~mm}$ at a height of $200 \mathrm{~m}$ and $0.52 \mathrm{~mm}$ at a height of $2,400 \mathrm{~m}$.

The maximum precipitation intensities recorded in the rain event occur at levels above $1,000 \mathrm{~m}$, while the maximum fall speeds are found at levels below $700 \mathrm{~m}$. The points of maximum intensities in each of the precipitation intervals detected decrease in height and magnitude; that is, as time passes, the maximum precipitation intensities are registered at a lower height and are less intense.

The three devices used, a disdrometer, a rain gauge, and a Micro Rain Radar (MRR), determine the rain rate indirectly by measuring different parameters and at different sampling points in the atmosphere. In doing so, the disdrometer and rain gauge measure very similar precipitation intensity values, whereas the MRR measures different precipitation volumes when extreme precipitation intensities are considered.

\section{Conflict of Interests}

The authors declare that there is no conflict of interests regarding the publication of this paper.

\section{Acknowledgments}

The authors would like to thank Dr. Noelia Ramón for translating this paper into English. This study was partially supported by the Spanish MINECO (Grants TEC2014-57821$\mathrm{R}$ and CGL2014-52556-R). E. Alonso-Blanco acknowledges the FPI grant to carry out the doctoral thesis/Ph.D. at the Research Centre for Energy, Environment and Technology (CIEMAT).

\section{References}

[1] M. T. Chahine, "The hydrological cycle and its influence on climate," Nature, vol. 359, no. 6394, pp. 373-380, 1992.

[2] M. Fernández-Raga, C. Palencia, C. Tomás, A. I. Calvo, A. Castro, and R. Fraile, "Rain research with disdrometers: a bibliometric review," Atmospheric Measurement Techniques Discussions, vol. 4, no. 5, pp. 6041-6068, 2011.

[3] A. A. Alonge and T. J. Afullo, "Regime analysis of rainfall dropsize distribution models for microwave terrestrial networks," IET Microwaves, Antennas \& Propagation, vol. 6, no. 4, pp. 393403, 2012.

[4] A. R. Jameson, "A bayesian method for upsizing single disdrometer drop size counts for rain physics studies and areal applications," IEEE Transactions on Geoscience and Remote Sensing, vol. 53, no. 1, pp. 335-343, 2015.

[5] M. Angulo-Martínez and A. P. Barros, "Measurement uncertainty in rainfall kinetic energy and intensity relationships for soil erosion studies: an evaluation using PARSIVEL disdrometers in the Southern Appalachian Mountains," Geomorphology, vol. 228, no. 1, pp. 28-40, 2015.

[6] R. Fraile, A. Castro, M. Fernández-Raga, C. Palencia, and A. I. Calvo, "Error in the sampling area of an optical disdrometer: consequences in computing rain variables," The Scientific World Journal, vol. 2013, Article ID 369450, 8 pages, 2013.

[7] M. Fernández-Raga, R. Fraile, J. J. Keizer et al., “The kinetic energy of rain measured with an optical disdrometer: an application to splash erosion," Atmospheric Research, vol. 96, no. 2-3, pp. 225-240, 2010.

[8] R. Harikumar, S. Sampath, and V. S. Kumar, "An empirical model for the variation of rain drop size distribution with rain rate at a few locations in southern India," Advances in Space Research, vol. 43, no. 5, pp. 837-844, 2009.

[9] T. Ushiyama, K. K. Reddy, H. Kubota, K. Yasunaga, and R. Shirooka, "Diurnal to interannual variation in the raindrop size distribution over Patau in the western tropical Pacific," Geophysical Research Letters, vol. 36, no. 2, Article ID L02810, 2009.

[10] G. Peters, B. Fischer, and T. Andersson, "Rain observations with a vertically looking Micro Rain Radar (MRR)," Boreal Environment Research, vol. 7, no. 4, pp. 353-362, 2002.

[11] S. Y. Matrosov, "Attenuation-based estimates of rainfall rates aloft with vertically pointing Ka-band radars," Journal of Atmospheric and Oceanic Technology, vol. 22, no. 1, pp. 43-54, 2005.

[12] G. Peters, B. Fischer, H. Münster, M. Clemens, and A. Wagner, "Profiles of raindrop size distributions as retrieved by microrain radars," Journal of Applied Meteorology, vol. 44, no. 12, pp. 19301949, 2005.

[13] J. Bendix, R. Rollenbeck, and C. Reudenbach, "Diurnal patterns of rainfall in a tropical Andean valley of southern Ecuador as seen by a vertically pointing K-band Doppler radar," International Journal of Climatology, vol. 26, no. 6, pp. 829-846, 2006.

[14] P. Saavedra, A. Battaglia, and C. Simmer, "Partitioning of cloud water and rainwater content by ground-based observations with the Advanced Microwave Radiometer for Rain Identification (ADMIRARI) in synergy with a micro rain radar," Journal of Geophysical Research: Atmospheres, vol. 117, no. 5, Article ID D05203, 2012.

[15] Y. Chen, H. Liu, J. An, L. Görsdorf, and F. H. Berger, "A field experiment on the small-scale variability of rainfall based on a network of micro rain radars and rain gauges," Journal of Applied Meteorology and Climatology, vol. 54, no. 1, pp. 243-255, 2015.

[16] A. Waldvogel, “The $\mathrm{N}_{0}$ jump of raindrop spectra," Journal of the Atmospheric Sciences, vol. 31, no. 4, pp. 1067-1078, 1974.

[17] G. Lee, A. W. Seed, and I. Zawadzki, "Modeling the variability of drop size distributions in space and time," Journal of Applied Meteorology and Climatology, vol. 46, no. 6, pp. 742-756, 2007. 
[18] R. Uijlenhoet, J. A. Smith, and M. Steiner, "The microphysical structure of extreme precipitation as inferred from groundbased raindrop spectra," Journal of the Atmospheric Sciences, vol. 60, no. 10, pp. 1220-1238, 2003.

[19] E. A. Brandes, G. Zhang, and J. Sun, "On the influence of assumed drop size distribution form on radar-retrieved thunderstorm microphysics," Journal of Applied Meteorology and Climatology, vol. 45, no. 2, pp. 259-268, 2006.

[20] G. Zhang, J. Sun, and E. A. Brandes, "Improving parameterization of rain microphysics with disdrometer and radar observations," Journal of the Atmospheric Sciences, vol. 63, no. 4, pp. 1273-1290, 2006.

[21] J. S. Marshall and W. M. Palmer, "The distribution of raindrops with size,” Journal of Meteorology, vol. 5, no. 4, pp. 165-166, 1948.

[22] R. S. Sekhon and R. C. Srivastava, "Doppler radar observations of drop-size distributions in a thunderstorm," Journal of the Atmospheric Sciences, vol. 28, no. 6, pp. 983-994, 1971.

[23] R. E. Gunn and J. S. Marshall, "The effect of wind shear on falling precipitation," Journal of Meteorology, vol. 12, no. 4, pp. 339-349, 1955.

[24] J. Joss and E. G. Gori, "Shapes of raindrop size distributions," Journal of Applied Meteorology, vol. 17, no. 7, pp. 1054-1061, 1978.

[25] C. W. Ulbrich, "Natural variations in the analytical form of the raindrop size distribution," Journal of Climate and Applied Meteorology, vol. 22, no. 10, pp. 1764-1775, 1983.

[26] P. T. Willis, "Functional fits to some observed drop size distributions and parameterization of rain," Journal of the Atmospheric Sciences, vol. 41, no. 9, pp. 1648-1661, 1984.

[27] G. Feingold and Z. Levin, "The lognormal fit to raindrop spectra from frontal convective clouds in Israel," Journal of Climate \& Applied Meteorology, vol. 25, no. 10, pp. 1346-1363, 1986.

[28] X. Wang, L. Zhang, and M. D. Moran, "Uncertainty assessment of current size-resolved parameterizations for below-cloud particle scavenging by rain," Atmospheric Chemistry and Physics, vol. 10, no. 12, pp. 5685-5705, 2010.

[29] R. Fraile and E. García-Ortega, "Fitting an exponential distribution," Journal of Applied Meteorology, vol. 44, no. 10, pp. 1620$1625,2005$.

[30] A. Tokay and P. G. Bashor, "An experimental study of smallscale variability of raindrop size distribution," Journal of Applied Meteorology and Climatology, vol. 49, no. 11, pp. 2348-2365, 2010.

[31] O. Geoffroy, A. P. Siebesma, and F. Burnet, "Characteristics of the raindrop distributions in RICO shallow cumulus," Atmospheric Chemistry and Physics, vol. 14, no. 19, pp. 10897-10909, 2014.

[32] L. Liao, R. Meneghini, and A. Tokay, "Uncertainties of GPM DPR rain estimates caused by DSD parameterizations," Journal of Applied Meteorology and Climatology, vol. 53, no. 11, pp. 25242537, 2014.

[33] C. E. Wainwright, D. T. Dawson II, M. Xue, and G. Zhang, "Diagnosing the intercept parameters of the exponential drop size distributions in a single-moment microphysics scheme and impact on supercell storm simulations," Journal of Applied Meteorology and Climatology, vol. 53, no. 8, pp. 2072-2090, 2014.

[34] M. Fernández-Raga, A. Castro, C. Palencia, A. I. Calvo, and R. Fraile, "Rain events on 22 October 2006 in León (Spain): drop size spectra," Atmospheric Research, vol. 93, no. 1-3, pp. 619-635, 2009.

[35] D. Atlas, R. C. Srivastava, and R. S. Sekhon, "Doppler radar characteristics of precipitation at vertical incidence," Reviews of Geophysics, vol. 11, no. 1, pp. 1-35, 1973.
[36] G. B. Foote and P. S. du Toit, "Terminal velocity of raindrops aloft," Journal of Applied Meteorology, vol. 8, no. 2, pp. 249-253, 1969.

[37] R. Gunn and G. D. Kinzer, "The terminal velocity of fall for water droplets in stagnant air," Journal of Meteorology, vol. 6, no. 4, pp. 243-248, 1949.

[38] Metek, MRR Physical Basics, Meteorologische Messtechnik, 2005.

[39] L. Cheng, M. English, and R. Wong, "Hailstone size distributions and their relationship to storm thermodynamics," Journal of Climate \& Applied Meteorology, vol. 24, no. 10, pp. 1059-1067, 1985.

[40] J. Dessens, R. Fraile, V. Pont, and J. L. Sánchez, "Day-of-theweek variability of hail in Southwestern France," Atmospheric Research, vol. 59-60, pp. 63-76, 2001.

[41] R. Fraile, A. Castro, L. López, J. L. Sánchez, and C. Palencia, “The influence of melting on hailstone size distribution," Atmospheric Research, vol. 67-68, pp. 203-213, 2003.

[42] G. Montero-Martínez, A. B. Kostinski, R. A. Shaw, and F. García-García, "Do all raindrops fall at terminal speed?" Geophysical Research Letters, vol. 36, no. 11, Article ID L11818, 2009.

[43] P. García-Vila, A. Benarroch, P. Garcia, and J. M. Riera, "Micro rain radar measurements of rainfall in Madrid," in Proceedings of the 3rd European Conference on Antennas and Propagation (EuCAP '09), pp. 676-680, Berlin, Germany, March 2009.

[44] B. Hennemuth, A. Weiss, J. Bösenberg et al., "Quality assessment of water cycle parameters in REMO by radar-lidar synergy," Atmospheric Chemistry and Physics, vol. 8, no. 2, pp. 287-308, 2008. 

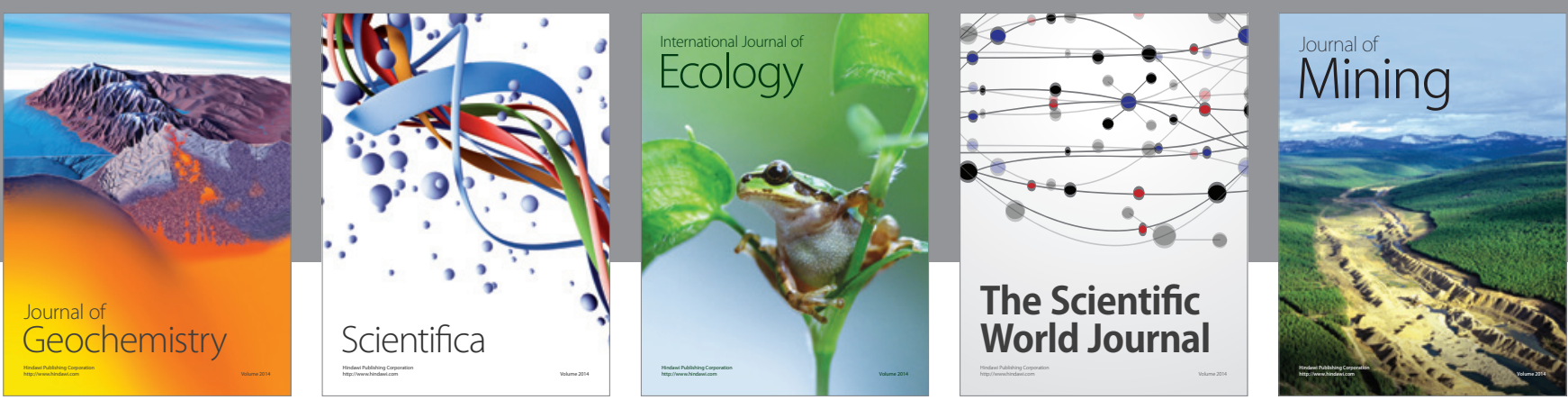

The Scientific World Journal
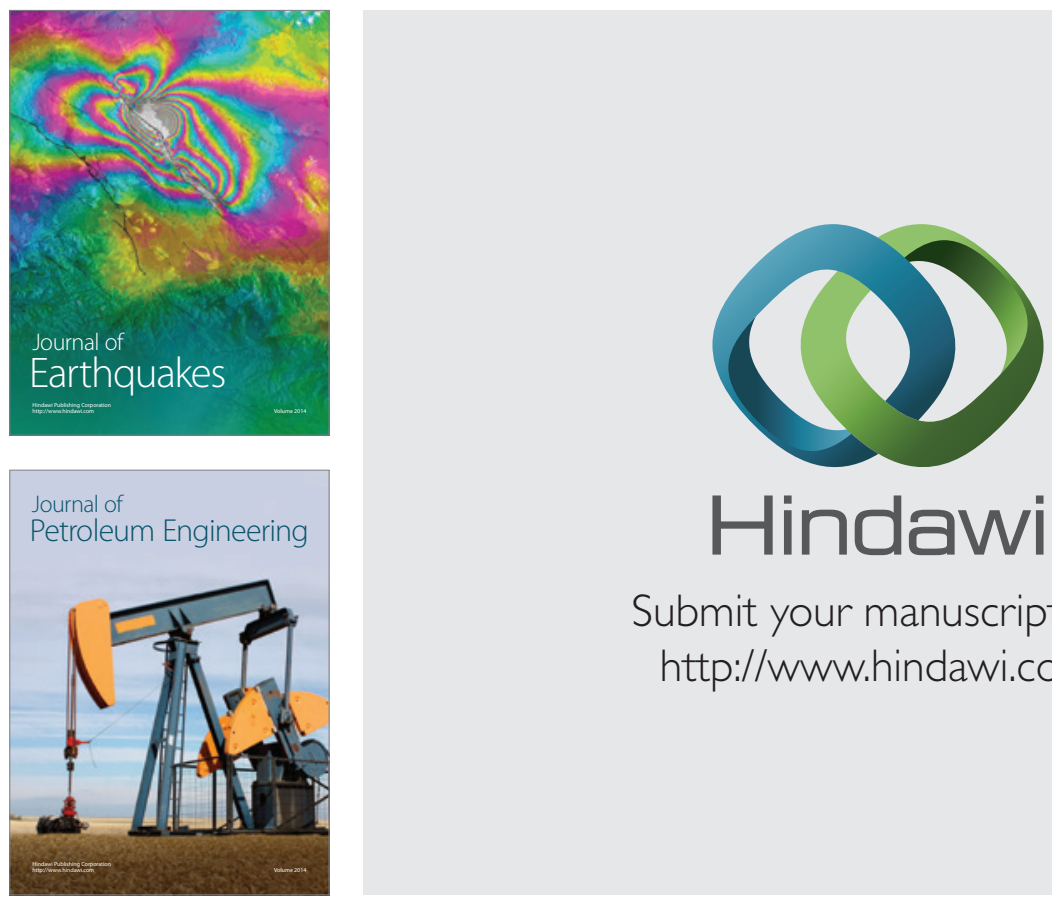

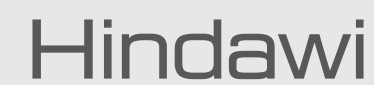

Submit your manuscripts at

http://www.hindawi.com
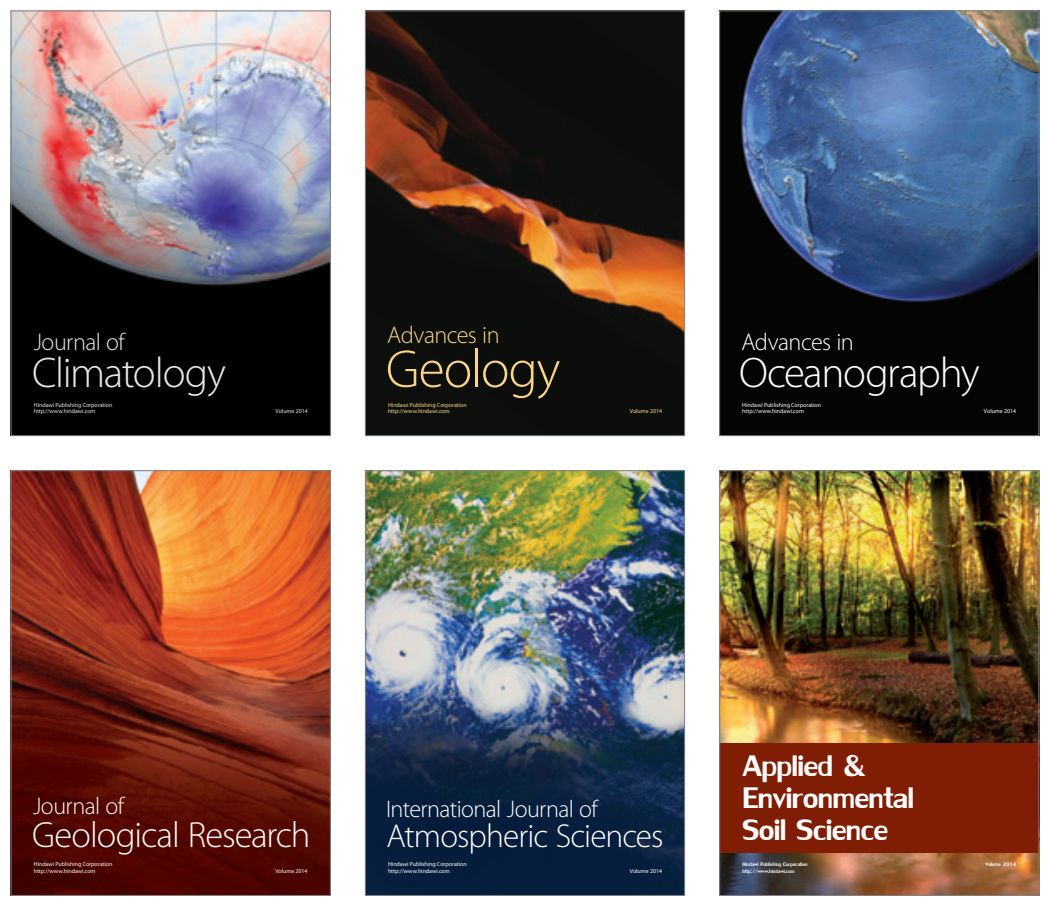
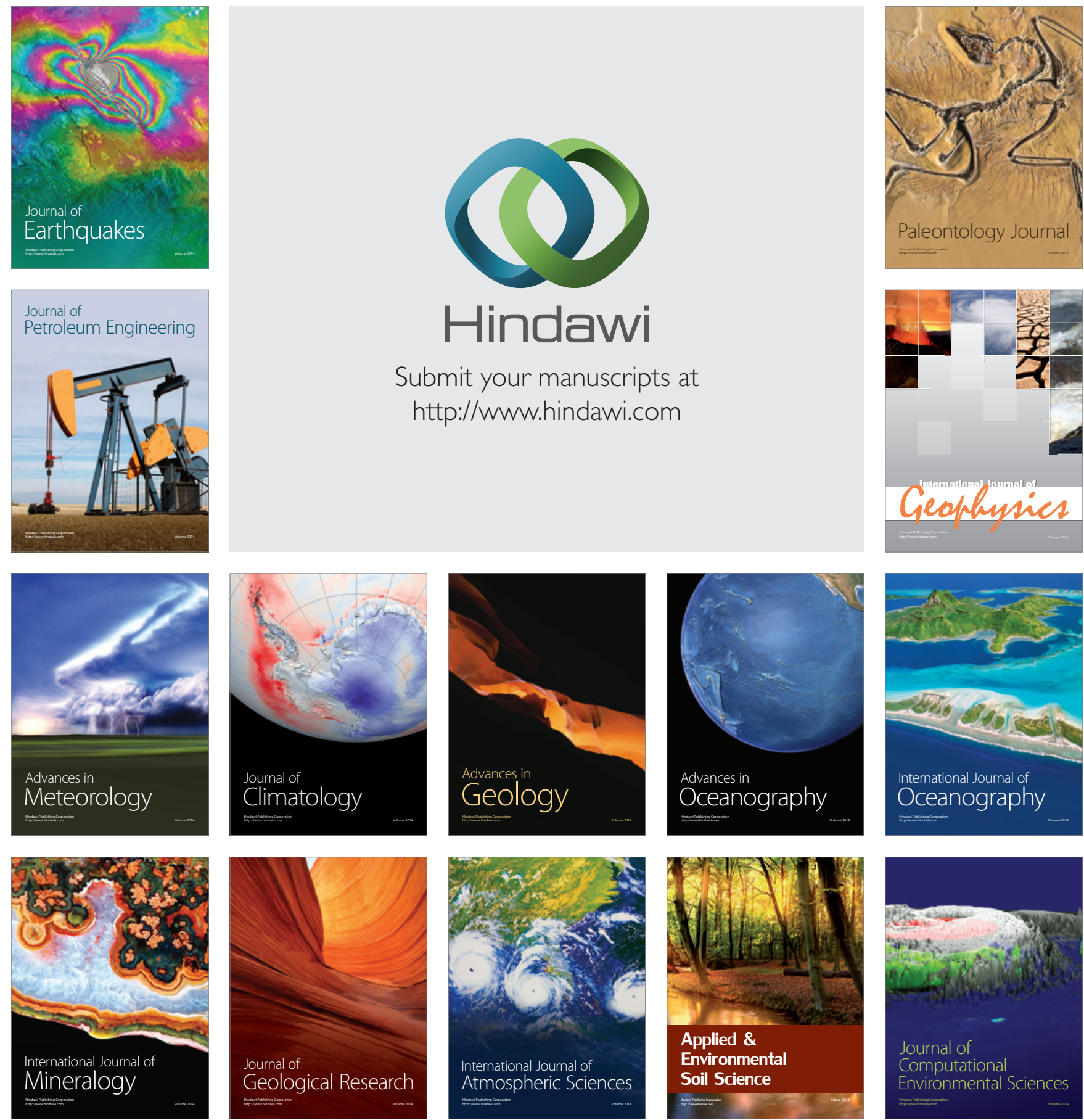